\title{
CLOSED-CHEST CORONARY ARTERY BYPASS GRAFTING ON THE BEATING HEART WITH THE USE OF A COMPUTER-ENHANCED SURGICAL ROBOTIC SYSTEM
}

\author{
W. Douglas Boyd, MD, Reiza Rayman, MD, Nimesh D. Desai, BSc, Alan H. Menkis, MD, Wojciech Dobkowski, MD, \\ Sugantha Ganapathy, MD, Bob Kiaii, MD, George Jablonsky, MD, F. Neil McKenzie, MD, and Richard J. Novick, MD, \\ London, Ontario, Canada
}

\begin{abstract}
Significant advances have been made in computer-assisted robotic coronary surgery in the past 2 years. Although limited success has been achieved with totally endoscopic, robotassisted bypass on the arrested heart, the ultimate objective is to perform a beating-heart procedure. To date, technical limitations have prevented this goal from being accomplished. We describe our initial clinical experience using robotic instrumentation and voice-controlled camera guidance (Zeus; Computer Motion Inc, Goleta, Calif) in performing closedchest, beating-heart coronary artery bypasses.

Patients and methods. The Zeus endoscopic instrument control system is a supervised online robotic system consisting of three components: a surgeon's console, a computer controller,
\end{abstract}

From the Division of Cardiothoracic Surgery, London Health Sciences Centre, University of Western Ontario, London, Ontario, Canada.

Received for publication March 20, 2000; accepted for publication June 16, 2000.

Address for reprints: W. Douglas Boyd, MD, Director, Minimally Invasive Surgery and Robotics, London Health Sciences Centre, 339 Windermere Rd, London, Ontario, Canada, N6A 5A5 (Email: boyd@ robosurgeon.com).

J Thorac Cardiovasc Surg 2000;120;807-9

Copyright (C) 2000 by The American Association for Thoracic Surgery

$0022-5223 / 2000 \$ 12.00+0 \quad \mathbf{1 2 / 5 4 / 1 0 9 5 4 1}$

doi: $10.1067 / \mathrm{mtc} .2000 .109541$ and three interactive table-mounted instrument manipulators. Details of this system have been previously described. ${ }^{1}$

Starting September 18, 1999, 18 patients with single-vessel coronary disease involving the left anterior descending coronary artery underwent beating-heart minimally invasive coronary artery bypass grafting with telerobotic assistance after approval by the university's institutional ethics committee. Totally robotic, closed-chest procedures were completed in 6 male patients and are the subject of this report.

After establishment of general anesthesia with a doublelumen endotracheal tube, each patient was placed in a $45^{\circ}$ right lateral decubitus position. The left arm was abducted to permit the insertion of three 5-mm access ports, while avoiding external robotic arm collisions. The left internal thoracic artery (LITA) was identified and dissected as a pedicle from the first to sixth ribs with voice-activated robotic and video assistance using the Harmonic Scalpel (Ethicon EndoSurgery, Inc, Somerville, NJ). During the procedure, warm carbon dioxide gas was insufflated into the pleural cavity up to a pressure of 5 to $10 \mathrm{~mm} \mathrm{Hg}$. The left anterior descending coronary artery (LAD) was stabilized with a prototype articulating endoscopic stabilizer (Fig 1). A specially designed sternal elevator was used in 3 of the patients to increase anteroposterior intrathoracic working space. A 5-mm $0^{\circ}$ endoscope and assistant instruments were passed through working ports. The patients were then systemically heparinized and the LAD prepared for anastomosis. The LITA 

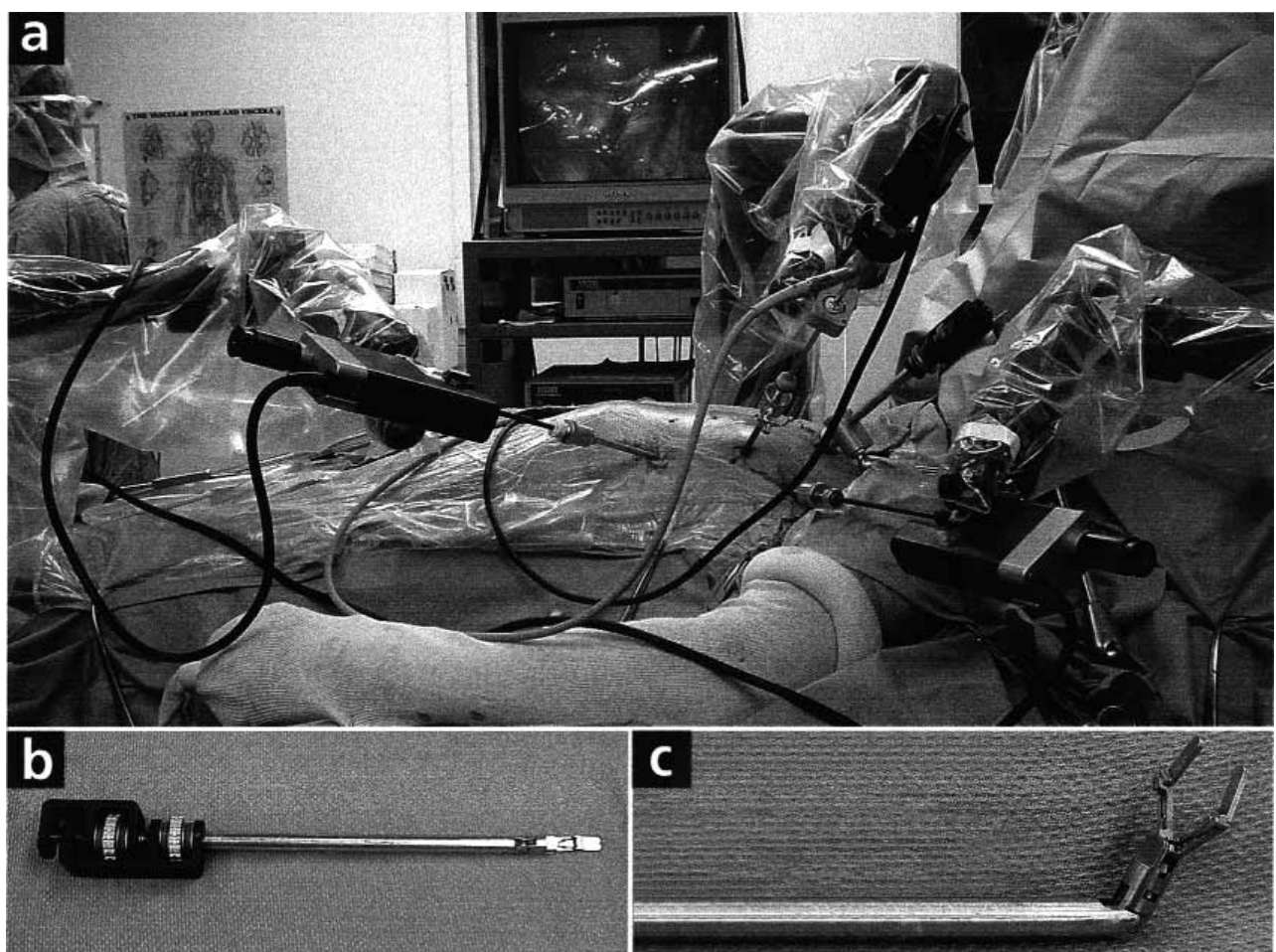

Fig 1. a, Endoscopic stabilization in place. b, Insertion configuration. c, Stabilization configuration.

was controlled with an endoscopic bulldog clamp. The Harmonic Scalpel and dissector were replaced by the Zeus needle driver and forceps, and robotic instrument working angles were verified. In all but 1 patient, the LAD arteriotomy, intraluminal shunt placement, and anastomoses were completed with robotic telemanipulation. Proximal and distal coronary snares were used in all patients. The end-to-side anastomosis was performed in each case by means of custom-made, double-armed 8-0 polytetrafluoroethylene sutures (W. L. Gore \& Associates, Inc, Flagstaff, Ariz) that were $7 \mathrm{~cm}$ in length. At the end of the procedure, blood flow through the LITA graft was assessed with a transit-time ultrasound probe (Transonic Systems, Ithaca, NY). A No. 20 chest tube was inserted through the 5-mm camera port site before wound closure (Fig 2). All patients underwent angiography and clinical reassessment postoperatively.

Results. The study included 6 men with an average age of $59.8 \pm 8.5$ years. LITA harvest time averaged $65.3 \pm 17.6$ minutes (range 50-91 minutes). The time required for the anastomosis was $55.8 \pm 13.5$ minutes (range 40-74 minutes). Intraoperative transit time flows averaged $28.3 \pm 13.2$ $\mathrm{mL} / \mathrm{min}$ (range $12-46 \mathrm{~mL} / \mathrm{min}$ ). Median operative time for the procedure was 6 hours (range 4.5-7.5 hours). Patients were intubated for an average of $8.5 \pm 8.3$ hours (range 0 23 hours), and all but 1 patient were discharged to the ward on the first postoperative day. All patients had angiographically confirmed patent grafts before leaving the hospital. Of the 6 grafts studied, 5 were of excellent quality and 1 had a $50 \%$ stenosis in the region of the distal snare site. The average length of hospital stay was $4.0 \pm 0.9$ days. One patient was readmitted to a peripheral hospital with pericarditis 4 days after the operation. All patients are free from angina, have returned to work, and have normal exercise capacity at a mean follow up of $145.3 \pm 29.6$ days.

Discussion. Robotic anastomosis has been successfully used in human trials on the cardioplegia-arrested heart through ports or large incisions. ${ }^{1-3}$ This series presents our initial clinical experience with endoscopic coronary artery bypass surgery on the beating heart in a closed chest with the use of remote robotic telemanipulation. The Zeus robotic telemanipulation system facilitated the closed-chest anastomosis by allowing precision and dexterity that is not possible with manual surgical instruments. ${ }^{2}$ The shunts improved hemostasis and provided a valuable needle depth landmark when performing endoscopic anastomoses with 2-dimensional cameras. The extended anastomotic times resulted from a dynamic working environment, limited working space and visual fields, and restricted assistant access. The working angles obtained by the robotic instruments after port placement were critical to the success of these cases.

Although 3-dimensional visualization systems may improve surgical video dexterity by improving motion control along the visual ( $\mathrm{z}$ ) axis, present generation 3-dimensional endoscopes are at least $10 \mathrm{~mm}$ in diameter. In our experience, intrathoracic space in the anteroposterior plane can be significantly limited in closed-chest operations, necessitating the use of smaller 5-mm 2-dimensional endoscopes with 30 degrees of angulation.

We found the most difficult part of the endoscopic procedure to be the "setup" for the robotic endoscopic anastomo- 


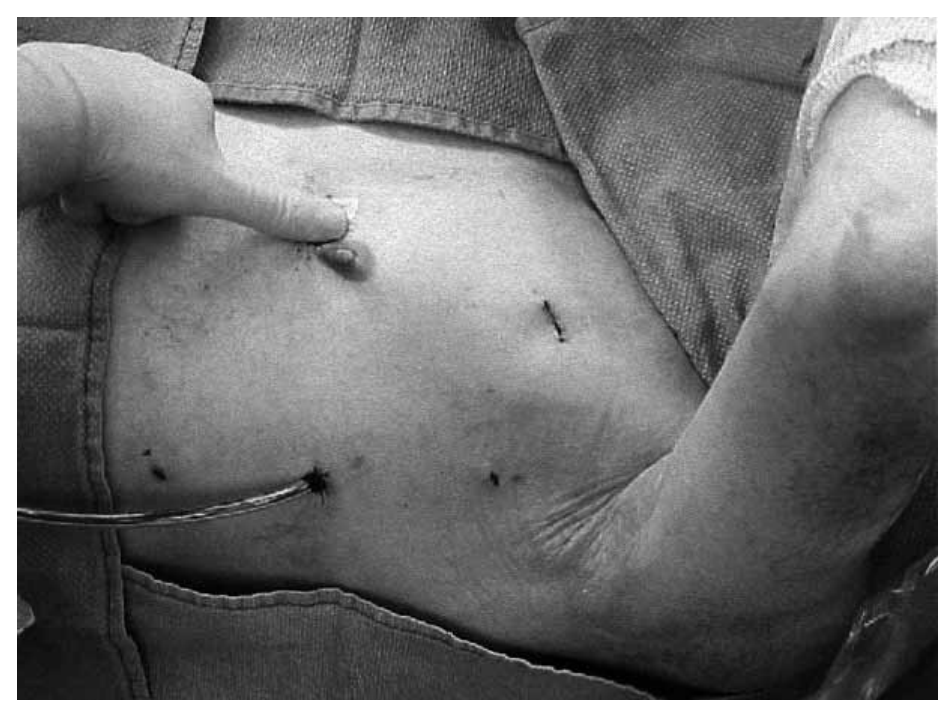

Fig 2. Postoperative incisions.

sis, that is, the multiple tasks that must be performed between LITA takedown and construction of the LITA-LAD bypass. Because of all the physiologic and anatomic variables, this part of the procedure is the most difficult to model in either animal or cadaver studies.

Totally endoscopic robotic coronary surgery carries a great potential to improve our minimally invasive surgical results even further. This article reports our early results on a small group of highly selected patients undergoing single-vessel bypass grafting. Robotic technology is still in a phase of evolution, and enormous challenges remain to make this a widely applicable, easy to perform procedure. For future surgeons to adopt these computer-assisted approaches, however, longterm graft patency, safety, cost reduction, and rapid recovery must be shown. Further clinical trials are needed to define which patients will derive the greatest benefit from this evolving method of myocardial revascularization.

\section{REFERENCES}

1. Damiano RJ Jr, Ehrman WJ, Ducko CT, Tabaie HA, Stephenson ER, Kingsley CP, et al. Initial United States clinical trial of robotically assisted endoscopic coronary artery bypass grafting. J Thorac Cardiovasc Surg 2000;119:77-82.

2. Reichenspurner H, Boehm DH, Gulbins H, Detter C, Damiano R, Mack M, et at. Robotically assisted endoscopic coronary artery bypass procedures without cardiopulmonary bypass. J Thorac Cardiovasc Surg 1999;118:960-1.

3. Mohr FW, Falk V, Diegeler A, Autschbach R. Computer-enhanced coronary artery bypass surgery. J Thorac Cardiovasc Surg 1999;117:1212-4 